\title{
A Study on Students' Learning Motivation of EFL in Taiwanese Vocational College
}

\author{
Jin-Jun Fan \\ Senior Lecturer, National Pingtung Institute of Commerce, Taiwan \\ E-mail: jinjun@npic.edu.tw \\ Hsiang-Yung Feng (Corresponding author) \\ Assistant Professor and Ph. D. Faculty Member \\ Institute of Economic and Social Studies, National United University, Taiwan \\ E-mail: hyfeng@nuu.edu.tw
}

Accepted: May 5, 2012 Published: June 17, 2012

Doi:10.5296/ijld.v2i3.1791 URL: http://dx.doi.org/10.5296/ijld.v2i3.1791

\begin{abstract}
Due to globalization, the importance of English cannot be overemphasized. Most teachers would assume that the motivation for students to learn English would be stronger than before. The purpose of this study is to explore the English learning motivation among vocational college students of different systems. The aim of the thesis was to understand students' learning motivation of EFL, and compare the motivation in different students' background or different systems of vocational college. The results showed that there were no differences on different systems in vocational college, gender and background of high school for students' learning motivations. The results also found that there were stronger statistically significant between learning motivations and learning achievements.
\end{abstract}

Keywords: English as a Foreign Language (EFL), Learning Motivation, Vocational Education 


\section{Introduction}

Due to globalization, the importance of English cannot be overemphasized. Most teachers would assume that the motivation for students to learn English would be stronger than before. The purpose of this study is to explore the English learning motivation among vocational college students of different systems.

In Taiwan, there are many vocational colleges for vocational high school graduates to attend. There are different systems within vocational colleges. Most vocational schools have day time and night school. These colleges also provide students with two-year and four-year programs. In this paper the writer will take students at National Ping Tung Institute of Commerce as subjects. Around 109 students will be involved in this study. Half of them attend night school and most of them hold a full day time job. However, the other half of the students was day time students with no jobs or part time job. The students at different school system basically received about six -year English instruction at junior high and senior vocational high schools. The hours of English course they have now are three hours each week. The writer would like to assume that students attending night school would be more strongly more strongly motivated to learn English since they have a full-time job during day time and probably their work will require them to use English. As for the day-time college students, their motivation to learn English would not be as strongly as those at night school.

\section{Literature Review}

\subsection{Vocational Education in Taiwan}

Vocational education or vocational education and training (VET) is an education that prepares trainees for jobs that are based on manual or practical activities, traditionally non-academic, and totally related to a specific trade, occupation, or vocation. In Taiwan, this education system was known as the "technical and vocational education". Early to coincide with Taiwan set up economic development, with the goal of fostering practical technical talents and skills as a guide for the course content to, this is the "narrow" technical and vocational education. After the accession to the WTO, the impact of industrialization, and to face the challenges of the knowledge economy, to General technical and vocational education shall be set to: "career preparation education", prepared to engage in some kind of professional learning, which provides professional competence, attitudes and ideals of education, which belongs to technical and vocational education.

Obviously foreign language learning and teaching were not the importance course in Taiwan Vocational Education past years. Department of Technological \& Vocational Education in Taiwan Ministry of Education set up Information Centre for International Cooperation and Exchange to promote students foreign language ability from 2008. According to the National Foreign Language Communities Standards (1999), students are expected to use the target language within and outside of the school setting for personal enjoyment and enrichment. There are five main goals set up in the National Standards in Foreign Language Education Project (1996) which are "communication," "cultures," "connection," "comparisons," and 
"communities" for EFL (English as a Foreign Language) students to reach and succeed in. Thus, "meeting the standards of the communication goal is essential to the accomplishment of the other four goals. Through communication, learners develop an understanding of the cultures for which the target language is the common code. They make connections to other knowledge and engage in analytic comparisons which can help to develop the insight and perspective into their own and others' languages and cultures (Liu, 2008).

\subsection{Learning Motivation and EFL}

Learning motivation "refers to a student's willingness, need, desire and compulsion to participate in, and be successful in, the learning process". It is what gets students to engage in academic activities, keeps them trying when things get difficult, and determines how much they learn (Bomia et al. 1997).

Among theories and approaches to student motivation, some tackle the problem from a psychological perspective. Here is a brief overview:

- Behavioural Theory: In B.F. Skinner's view (1953), learning motivation is a result of reinforcement. Students who have been rewarded for learning, for example, by receiving good grades or the praise of people important to them will be motivated to learn (Skinner, 1953, as cited in Slavin, 1994).

- Humanistic Theory: From A.H. Maslow's perspective (1954), learning motivation is a satisfaction of needs and an attempt to fulfill one's total potential as a human being. Students who feel they are loved and that they are capable are more likely to have a stronger motivation to search for knowledge and understanding for their own sake or a stronger desire to develop their own potential (Maslow, 1954, as cited in Eggen, 2004).

- Attribution Theory: B. Weiner (1992) defined learning motivation as a matter of how learners account for their past successes or failures. Students who attribute their success or failure to effort or learning strategies rather than to their perception of their ability, luck and/or task difficulty will be more eager to learn and will not give up easily (Weiner, 1992, as cited in Eggen, 2004).

- Expectancy-value Theory: With reference to J.S. Eccles and A. Wigfield (1995), learning motivation is learners' expectation and valuing of success. Students will be more involved in learning if they value either the outcome or the process of learning and they expect that they will be successful (Eccles and A. Wigfield, 1995, as cited in Biggs and Moore, 1993).

Scholars defined motivations into within made sexual motivation and outside induced sexual motivation, within made sexual motivation is means behaviour of power is individual automatically spontaneous of, is a does not needs forces spur and urged of learning power, needs, and curious, and combative is within made of motivation. Outside induced motivation is means external environment of stimulus and produced of learning power, needs through forces of urged, As far as the learning, induced from outside the engine in a more motivated 
more sustainability, learning outcomes are better, thus induced from outside the schools leading students motivation into the engine, the students from passive learning environment for the desired by parents, teacher supervision, into self-direction in learning situations.

Wu \& Lin's study showed that English learning motivation is the mediator of English learning environment and English learning strategies (Wu \& Lin, 2009). Wu explores the relationship among English learning motivation, action control, meta-cognition, and learning performance of college students, and found that college students' learning performance is significantly influenced by action control and meta-cognition ( $\mathrm{Wu}, 2009)$. Wu's research found out that after the teaching activity, students in the experiment group and the control group were significantly different in their motivation of learning English. Besides, there are also significant differences in other aspects such as their volitional control, metacognition, and learning achievement (Wu, 2004).

According to above studies, it showed that students' motivation is the most important key in English teaching and counselling. It can improve student learning through the English learning environment for English learning motivation and English learning strategies. This study focused on vocational college students' learning motivation of EFL, and compared difference on different systems of same school.

\section{Methods}

\subsection{Survey Administration and Sampling}

The aim of the thesis was to understand students' learning motivation of EFL, and compare the motivation in different students' background or different systems of vocational college. In this study, the learning motivation scale of EFL taken from Wu and Cheng (1922), which translated from Motivation and Strategies for Learning Questionnaire (MSLQ) by Pintrich, Smith and McKeachie (1991). This scale was tested and verified by Wu, Cheng (1922) and subsequent scholars in Taiwan (Wu, 2004; Wu, 2009; Li, Lin, \& Lin, 2007; Wu, \& Lin, 2009), displayed good quality and validity. It contained three parts (value, expectancy and affect) and 7 factors: extrinsic goal oriented, intrinsic goal oriented, task value, control beliefs about learning, self-efficacy, test anxiety and expectations of success. The test consisted of 35 items and was rated on a 5-point Likert scale ranging from 1 (not at all true of me) to 5 (very true of me).

The research sample was author's classrooms in National Pingtung Institute of Commerce, 109 students. Parts were four years undergraduate system, and parts were four years extension system. Almost students in extension system hold a full-time job; contrarily students in undergraduate system had no job or part-time job.

\subsection{Data Analysis}

Questionnaire was used in data collection. The questionnaire included 2 parts. In part 1 of the questionnaire survey, participants were required to fill-in personal information. And, the part 2 of the questionnaire was to ask student's learning motivation of EFL. The research utilized 
statistical analysis and SPSS software to examine this research hypothesis. The data analysis included: (1) Descriptive statistics, (2) t-test and (3) Canonical Analysis. Canonical analysis was used to assess the correlation between two sets of variables. The most widely used type of canonical analysis was Pearson correlation coefficient, which was also referred to as linear or product-moment correlation. Correlation coefficient was a term that refers to the strength of a relationship between two variables.

\section{Analysis and Results}

\subsection{Demographic Profile of Respondents}

The subjects who took part in this study were 107 students after ignored 2 students' incomplete questionnaire. Fifty-two (48.6\%) students enrolled at undergraduate system and fifty-five (51.4\%) at extension system. There were 40 males (37.4\%) and 67 females $(62.6 \%)$. Those students graduated from vocational high school in large part. The demographic profile data of respond students showed table 1.

Table 1: Participants' demographics $\quad(\mathrm{N}=107)$

\begin{tabular}{lll}
\hline Demographics & Frequency & Percentage \\
\hline System & & \\
$\quad$ Undergraduate system & 52 & $48.6 \%$ \\
$\quad$ Extension system & 55 & $51.4 \%$ \\
\hline Gender & & \\
$\quad$ Male & 40 & $37.4 \%$ \\
Female & 67 & $62.6 \%$ \\
\hline Background of High School & & \\
$\quad$ General high school & 10 & $9.3 \%$ \\
$\quad$ Vocational high school & 77 & $72.0 \%$ \\
$\quad$ Comprehensive high school & 20 & $18.7 \%$ \\
\hline
\end{tabular}

\subsection{Learning Motivation in EFL Study}

Learning motivation scale tested for homogeneity, the factor loadings less than 0.3 was deleted and leaving 25 items classified 6 factors. The reliability coefficients (Cronbach's alpha) ranged from 0.409 to 0.867 , which were considered acceptable values for this reliability test. In analyzing the data, the internal consistency of the remaining factors were quite good except extrinsic goal oriented factor, suitable for further analysis of the learning motivation.

Table 2 showed that the means of learning motivation factors were 3.346, 3.322, 3.400, 3.662, 2.940 and 2.730. The higher values were control beliefs about learning and task value, and the lower values were self-efficacy and expectations of success. The results indicated that the expectations of success and learning self-efficacy were relatively low, although students have high value of control of learning beliefs and assent task value. Further, students of different 
systems for EFL learning motivation were almost no statistical difference (see table 3 below), even gender, educational background were the same situation.

Table 2: Summary of measurement scales

\begin{tabular}{|c|c|c|c|}
\hline Factors & Mean & S.D. & Cronbech's $\alpha$ \\
\hline Extrinsic goal oriented & 3.346 & 0.722 & 0.409 \\
\hline Get good grades, I am most satisfied & 3.57 & 0.933 & \\
\hline I work hard to get a good grade even when I don't like a class & 3.12 & 0.887 & \\
\hline Intrinsic goal oriented & 3.322 & 0.612 & 0.704 \\
\hline I prefer class work that is challenging so I can learn new things. & 3.21 & 0.901 & \\
\hline It is important for me to learn what is being taught in this class & 3.74 & 0.757 & \\
\hline I expect to do very well in this class & 2.97 & 0.829 & \\
\hline $\begin{array}{l}\text { I was most satisfied with the English course content as possible } \\
\text { to thoroughly clear }\end{array}$ & 3.36 & 0.873 & \\
\hline Task value & 3.400 & 0.602 & 0.786 \\
\hline $\begin{array}{l}\text { I think I will be able to use what I learn in this class in other } \\
\text { classes }\end{array}$ & 3.36 & 0.840 & \\
\hline $\begin{array}{l}\text { Even when study materials are dull and uninteresting, I keep } \\
\text { working until I finish }\end{array}$ & 3.47 & 0.974 & \\
\hline I think that what we are learning in this class is interesting & 2.91 & 0.906 & \\
\hline $\begin{array}{l}\text { I think that what I am learning in this class is useful for me to } \\
\text { know }\end{array}$ & 3.89 & 0.744 & \\
\hline I like what I am learning in this class & 3.01 & 0.863 & \\
\hline Understanding this subject is important to me & 3.77 & 0.853 & \\
\hline Control beliefs about learning & 3.662 & 0.447 & 0.558 \\
\hline If I use the right way, I can learn English better & 3.97 & 0.606 & \\
\hline $\begin{array}{l}\text { I always try to understand what the teacher is saying even if it } \\
\text { doesn't make sense. }\end{array}$ & 3.62 & 0.668 & \\
\hline $\begin{array}{l}\text { If I study hard enough, I will understand the content of the } \\
\text { English class }\end{array}$ & 3.94 & 0.671 & \\
\hline $\begin{array}{l}\text { If I do not know the contents of the English class, it is because } \\
\text { I'm not hard }\end{array}$ & 3.79 & 0.789 & \\
\hline $\begin{array}{l}\text { If I have learned the contents of the English class, it is so easy } \\
\text { to learn }\end{array}$ & 2.99 & 0.937 & \\
\hline Self-efficacy & 2.940 & 0.586 & 0.712 \\
\hline I'm certain I can understand the ideas taught in this course & 2.42 & 0.869 & \\
\hline I know that I will be able to learn the material for this class & 2.97 & 0.874 & \\
\hline $\begin{array}{l}\text { I often choose paper topics I will learn something from even if } \\
\text { they require more work }\end{array}$ & 3.57 & 0.881 & \\
\hline I'm sure I can master the skills taught in English class & 2.53 & 0.861 & \\
\hline $\begin{array}{l}\text { Consider the degree of difficulty of the English class, the } \\
\text { teacher, and my personal skills, I will perform well }\end{array}$ & 3.21 & 0.810 & \\
\hline Expectations of success & 2.730 & 0.791 & 0.867 \\
\hline I think I will receive a good grade in this class & 2.70 & 0.892 & \\
\hline My study skills are excellent compared with others in this class & 2.68 & 0.907 & \\
\hline $\begin{array}{l}\text { I am sure I can do an excellent job on the problems and tasks } \\
\text { assigned for this class }\end{array}$ & 2.81 & 0.870 & \\
\hline
\end{tabular}




\section{Il Macrothink}

Table 3: System differences on learning motivation factors

\begin{tabular}{|c|c|c|c|c|c|c|}
\hline \multirow{2}{*}{$\begin{array}{l}\text { Learning motivation } \\
\text { (factors) }\end{array}$} & \multicolumn{2}{|c|}{ Undergraduate system } & \multicolumn{2}{|c|}{ Extension system } & \multirow{2}{*}{ t-value } & \multirow{2}{*}{ Sig. } \\
\hline & Mean & SD & Mean & SD & & \\
\hline Extrinsic goal oriented & 3.320 & 0.693 & 3.370 & 0.753 & -0.395 & 0.693 \\
\hline Intrinsic goal oriented & 3.346 & 0.465 & 3.300 & 0.729 & 0.388 & 0.699 \\
\hline Task value & 3.442 & 0.524 & 3.361 & 0.670 & 0.700 & 0.486 \\
\hline Control beliefs about learning & 3.650 & 0.421 & 3.673 & 0.474 & -0.262 & 0.794 \\
\hline Self-efficacy & 2.908 & 0.548 & 2.971 & 0.622 & -0.556 & 0.579 \\
\hline Expectations of success & 2.570 & 0.751 & 2.880 & 0.804 & -2.087 & $0.039 *$ \\
\hline
\end{tabular}

$* \mathrm{p}<0.1, * * \mathrm{p}<0.05, * * * \mathrm{p}<0.01$

\subsection{Learning Achievement and Needs}

Learning achievements included English course grades of last semester, self-assessment of English language proficiency. However, learning needs included English required proficiency in job and in life. We found extension system students' achievements of EFL were higher than day school students. Not only English course grades of last semester, but also the self-assessment of English language proficiency got higher grades. The test were significant, $\mathrm{t}=-2.191, \mathrm{p}=0.031$, and $\mathrm{t}=-2.155, \mathrm{p}=0.033$. Table 4 showed the differences on learning achievement and needs among different systems. As regards, both learning needs included English required proficiency in job and in life were not significant difference. It was very interesting that the needs of EFL got much higher scales than the achievements. The mean values of English required proficiency were 4.19 in job and 4.04 in life. The results indicated that almost vocational college students think EFL very important.

Table 4: System differences on learning achievement and needs

\begin{tabular}{lllllll}
\hline \multirow{2}{*}{$\begin{array}{l}\text { Achievement and } \\
\text { Needs }\end{array}$} & \multicolumn{2}{l}{ Undergraduate system } & \multicolumn{2}{l}{ Extension system } & \multirow{2}{*}{ t-value } & \multirow{2}{*}{ Sig. } \\
\cline { 2 - 6 } & Mean & SD & Mean & SD & & \\
\hline English score of last semester & 3.17 & 0.550 & 3.55 & 1.102 & -2.191 & $0.031^{* *}$ \\
Self-assessment of English & 2.00 & 0.714 & 2.31 & 0.767 & -2.155 & $0.033^{* *}$ \\
English required proficiency in job & 4.19 & 0.841 & 4.05 & 0.731 & 0.906 & 0.367 \\
English required proficiency in life & 4.04 & 0.862 & 4.15 & 0.621 & -0.739 & 0.461 \\
\hline
\end{tabular}

$* \mathrm{p}<0.1, * * \mathrm{p}<0.05, * * * \mathrm{p}<0.01$

The correlation between learning achievements, needs and motivation factors, showed table 5 below. Coefficients of correlation between English score of last semester and learning motivations of EFL were high and statistically significant expect self-efficacy motivation. Coefficients of correlation between self-assessment of English and intrinsic goal oriented, task value, self-efficacy, expectations of success learning motivations were statistically significant. It seemed that English language proficiency and achievement were caused by learning motivations; the stronger the motivation to learn will have higher academic achievement. 
In addition, coefficients of correlation between English required proficiency in job and learning motivations of EFL, intrinsic goal oriented and task value, were statistically significant. Further, Coefficient of correlation between English required proficiency in life and intrinsic goal oriented motivation was also significant. The results seemed that job and life need to use English were significant correlation with intrinsic goal oriented, task value of learning motivations.

Table 5: Correlation matrix between learning achievement, needs and motivation factors

\begin{tabular}{lllll}
\hline Learning motivation & $\begin{array}{l}\text { English } \\
\text { score of last } \\
\text { semester }\end{array}$ & $\begin{array}{l}\text { Self-assessment } \\
\text { of English }\end{array}$ & $\begin{array}{l}\text { English } \\
\text { required } \\
\text { proficiency } \\
\text { in job }\end{array}$ & $\begin{array}{l}\text { English } \\
\text { required } \\
\text { proficiency } \\
\text { in life }\end{array}$ \\
\hline Extrinsic goal oriented & $0.205^{*}$ & -0.024 & 0.158 & 0.158 \\
Intrinsic goal oriented & $0.339^{* * *}$ & $0.327^{* *}$ & $0.236^{*}$ & $0.300^{* *}$ \\
Task value & $0.235^{*}$ & $0.278^{* *}$ & $0.235^{*}$ & 0.157 \\
Control beliefs about learning & $0.283^{* *}$ & 0.150 & 0.172 & 0.169 \\
Self-efficacy & 0.186 & $0.364^{* * *}$ & 0.041 & 0.047 \\
Expectations of success & $0.264^{* *}$ & $0.457^{* * *}$ & 0.083 & 0.160 \\
\hline
\end{tabular}

$* \mathrm{p}<0.1, * * \mathrm{p}<0.05, * * * \mathrm{p}<0.01$

\section{Conclusion}

Learning motivation is a key factor in learning English as a foreign language. The study focused on learning motivation of vocational school students of in Taiwan. The results showed that there were no differences on different systems in vocational college, gender and background of high school for students' learning motivations. However, the learning motivations of students in Taiwanese vocational college were mainly control beliefs about learning, task value and intrinsic goal oriented. The results were different to general university students whose learning motivations were extrinsic and intrinsic goal oriented. The results also showed that there were stronger statistically significant between learning motivations and learning achievements, but little statistically significant between learning motivations and learning needs.

From the viewpoint of behavioural theory, learning motivation is a result of reinforcement. Enabling students to obtain achievement is the key to improving students' learning motivation in learning process. Both learning motivations and learning achievements were influenced by each other. Teachers giving students high grades was a good way to enhance students' learning motivations. And Maslow's perspective, learning motivation is a satisfaction of needs and an attempt to fulfill one's total potential as a human being. Students who feel they need English as a foreign language had stronger motivations to study. From expectancy-value theory, students will be more involved in learning if they value either the outcome or the process of learning. This study found that vocational school students had the low achievements and the lack of strong motivation of EFL although strong learning needs. 
Facing the impact of globalization, many countries make the international language of learning in education in order to promote the student's capability of foreign language. In Taiwan, the foreign language learning almost is English learning. After several years to learn English in class, students know the importance of EFL and have strong learning needs, but the learning achievements are still lower grade. By this study, the research results could provide the way to ameliorate the study of EFL. It is the important work of foreign language education to promote students' motivations and make the learning environment better.

\section{References}

Albright, J. J., \& Park, H. M. (2009). Confirmatory Factor Analysis using Amos, LISREL, Mplus, SAS/STAT CALIS*, from http://www.indiana.edu/ statmath

Chen, C.-F., \& Wu, C.-C. (2005). A Study on Overseas Travel Motivations and Market

Segmentation for the Seniors. Tourism Management Research, 5(1), 16.

Chen, K.-H. (2006). The Construction of Travel Behavior Model for Ecotourism - Travel Motivation as an Untermediated Variable. Journal of Leisure and Tourism Industry Research, 1(1), 18.

Cheng-min, C., \& Bor-wen, C. (2009). Relationship among Personality Traits, leadership behavior, and job street in nurses in Yunlin, Taiwan. China-USA Business Review, 8(4), 7.

Fu, Y.-C., Lu, L., \& Chen, S.-Y. (2009). Differentiating Personal Facilitators of Leisure Participation: Socio-demographics, Personality Traits, and the Need for Sociability. Journal of Tourism and Leisure Studies, 15(3), 16.

Hsieh, P.-S. (2010). The Internship Abroad Effects on Hospitality Management Major Students' Future Career Planning. (Master), National Tai-Chung Institute of Technology Tai-Chung, Taiwan. Available from Airiti AiritiLibrary database.

Jang, K. L., Llvesley, W. J., \& Vemon, P. A. (1996). Heritability of the Big Five Personality Dimensions and Their acets: A Twin Study. Journal of Personality, 64(3), 15.

Jou, J. Y. H., \& Wu, C. H. J. (2003). A Research on Leisure Farm Tourists' Motivation, Information Search Behavior, and Evaluation Criteria in Taiwan. Journal of Tourism Studies, 9(2), 23.

Lee, C.-S., \& Liu, D.-Y. (2011). Literature Review on seniors' Tourism Motivation and Constraint. Journal of Sport, Leisure and Hospitality Research, 6(2), 29.

Li, C. L., Lin, M. M. \& Lin, Y. C., (2007). A Study of the Relationship between Gender and English Learning Motivation-A Case Study of Elementary School Students in Pingtung County. Journal of Meiho Institute of Technology, Vol.26 No.1 pp.133 148.

Liao, M.-H., Lin, H.-M., Hung, L.-C., \& Wei, C.-K. (2009). Research on the Correlations between Organizational Context, Personality Traits and Motivation for Learning and Transfer - A Case Study on Administrative Personnel from One Hospital System in Taiwan. Journal of Management, 26(4), 13. 
Lou, J.-H., Chen, S.-H., Yu, H.-Y., Li, R.-H., Yang, C.-I., \& Eng, C.-J. (2010). The Influence of Personality Traits and Social Support on Male Nursing Student Life Stress: A Cross-Sectional Research Design. Journal of Nursing Research, 18(2), 9.

Lu, L., \& Kao, S.-F. (2009). Leisure Participation and Leisure Satisfaction: Moderating Effects of Personality Traits. Journal of Sport and Recreation Research, 3(3), 11.

Nohara, K., Norton, M., Saijo, M., \& Kusakabe, O. (2008). Overseas internships as a vehicle for developing a meta-level awareness regarding science communication. Journal of Science Communication, 7(1), 12.

Tsau, C. C., \& Hao, C. H., (2010). The Influence of the Elementary Students' Early English Learning Experience on their English Motivation and Academic Achievements. Journal of Educational Practice and Research, Vol. 23, No. 2, 95-124, Dec. 2010.

Wang, K.C. (2006). Motivations for Senior Group Package Tour Tourists. Journal of Tourism Studies, 12(2), 20.

Wu, C. J., (2004). A Study of the Effects of Cognitive-Affective-Volitional Integrated Language Learning Strategies on English Performance Journal of National Taipei Teachers College, Vol.17, No.1 (Mar. 2004) 227 250.

Wu, C. J., (2009). Learning Motivation, Action Control, Meta-cognition, and Learning Performance of College Students. Taiwan Education Academic Conference 2009.

Wu, C. J., Chang, Y. J. \& Lo, T. Y., (2009). The Relationship among English Learning Motivation, Action Control, Meta-cognition, and Academic Achievement of ECEC Department Students. Journal of the Educational Reserarch, No.5, p.55-82, Tzu-Chi University.

Wu, H. C., Huang, W.-S., Li, C.-L., \& Lee, Y.-F. (2007). Model Construction and Validation of Integrating Traveling Motivation, Satisfaction and Loyalty: A Case of Whale-Watching Activities in I-Lan County. Journal of Tourism Studies, 13(4), 21.

Wu, J. J., \& Cheng, B. L., (1992). Amendment to Motivated Strategies for Learning Questionnaire. Psychological Testing, Vol. 39.

Wu, Y. S., \& Lin, C. P., (2009). A Study of the Relationship among English Learning Environment, Learning Motivation and Learning Strategies of College Students. Academic Reports, Vol. 40, No. 2, Taipei Municipal University of Education.

Yen, C.-H., Huang, Y.-J., \& Chang, Y.-C. (2010). A study of tourist motivation, destination attraction, satisfaction of tourists in Nankunshen Daitianfu Temple. Journal of Rural Tourism Research, 4(2), 16. 